\section{Perinatal listeriosis}

Perinatal listeriosis was first reported by Burn in 1933 and is now estimated to affect one in 20000 births. ${ }^{1}$ About a quarter of the 424 reports from England, Wales, and Scotland in 1983 to 1985 were in children less than 1 month old, and half of these were neonatal infections (Communicable Disease Surveillance Centre, unpublished data).

Listeria monocytogenes is a short, Gram positive, nonsporing, motile rod whose isolation is enhanced at $4^{\circ} \mathrm{C}$. It is a facultative anaerobe, and there are four antigenic serotypes, of which types 1 and 4 are the main ones causing infection in man. ${ }^{2}$ The epidemiology of listeria infections has remained obscure: although the organism infects many different animals and has been cultured from soil and faeces, infection in man does not result primarily from direct contact with infected animals. ${ }^{3}$ Neonatal infection may be caused by cross infection, ${ }^{4}$ and outbreaks often occur in clusters ${ }^{5}$ or epidemics. ${ }^{6-10} L$ monocytogenes may be a normal resident of the intestinal tract with potentially pathogenic properties, which would explain why antibodies to listeria are common in healthy people. ${ }^{2}$ Rectal carriage by pregnant women was 10 times higher during an epidemic in New Zealand. ${ }^{9}$ In Israel the symptomless carriage of $L$ monocytogenes in the genital tract was associated with a history of recurrent abortion, ${ }^{11}$ but this was not confirmed in Britain ${ }^{12}$ or the United States. ${ }^{13}$

Listeric infection of the fetus during pregnancy is often associated with a non-specific, flu like, pyrexial illness in the mother. ${ }^{14}$ is Decidual microabscesses and characteristic foci of purulent villitis within the placenta have led some to believe that fetal infection is caused by the bloodborne transplacental passage of organisms from the mother ${ }^{1016}$; severe chorioamnionitis is, however, in keeping with an ascending pathway of infection. ${ }^{617}$. Fetal infection in early pregnancy results in abortion, and the extensive maceration seen at delivery, so soon after the maternal symptoms, suggests that the maternal bacteraemia may result from rather than be the cause of the fetal infection. ${ }^{2}$ Fetal infection later in pregnancy causes stillbirth ${ }^{15}$ or preterm labour associated with meconium stained liquor and an infected baby. ${ }^{6-10}$

Congenital listeria infection presents soon after birth as pneumonia and septicaemia, and $L$ monocytogenes was isolated from the vagina of $37 \%$ of mothers of such infants. ${ }^{1}$ The high mortality of $35-55 \%$ reflects associated prematurity. ${ }^{16-10}$ Microabscesses and granulomas containing the organism are found throughout the body at necropsy ${ }^{18}$ - particularly in the lungs, liver, and spleen-giving rise to the term granulomatosis infantiseptica. ${ }^{16} \mathrm{~A}$ high rate of disability among survivors has been reported, ${ }^{19}$ but this does not always occur. ${ }^{69}$ Neonatal infection, acquired during delivery from . the mother's genital tract ${ }^{14}$ or later by cross infection, ${ }^{14}$ presents as septicaemia and meningitis several days or even weeks after an uneventful birth..$^{719} \mathrm{~A}$ granulomatous macrocytic inflammation of the meninges may lead to microabscesses in the brain, but this form of neonatal listeriosis has a lower mortality, ${ }^{79}$ and survivors are unlikely to have neurological sequelae. ${ }^{919}$

Treatment of suspected neonatal infection usually begins before firm bacteriological confirmation. The combination of ampicillin or penicillin with gentamicin or kanamycin is more effective against listeria than other agents alone or in combination. ${ }^{82}$ Listeric septicaemia in the mother during pregnancy has been successfully treated with ampicillin, and such treatment prevented perinatal listeriosis. ${ }^{102}$ Success in managing this condition depends not so much on considering the diagnosis ${ }^{10}$ but more on the degree of fetal or neonatal infection at the time of presentation. ${ }^{15}$

JOHN A D SPENCER

Senior Lecturer and Consultant,

Royal Postgraduate Medical School Institute

of Obstetrics and Gynaecology,

Queen Charlotte's Maternity Hospital,

London W6 0XG

1 McLauchlin J. Listeria monocytogenes, recent advances in the taxonomy and epidemiology of listeriosis in humans. $\mathcal{f}$ Appl Bacteriol (in press).

2 Seeliger HPR, Finger H. Listeriosis. In: Remington JS, Klein JO, eds. Infectious diseases of the fetus and newborm infant. London: W B Saunders, 1976:333-65.

3 Gray ML, Killinger AH. Listeria monocytogenes and listeric infections. Bacteriological Reviews 1966;30:309-82.

4 Larsson S, Cederberg A, Ivarsson S, Svanberg L, Cronberg S. Listeria monocytogenes causing hospital-acquired enterocolitis and meningitis in newborn infants. BrMed $\mathcal{F}$ 1978;ii:473-4.

5 McLauchlin J, Audurier A, Taylor AG. Aspects of the epidemiology of human Listeria monocy togenes infections in Britain 1967-1984; the use of serotyping and phage typing. $J$ Med Microbiol 1986;22:367-77.

6 Becroft DMO, Farmer K, Seddon RJ, et al. Epidemic listeriosis in the newborn. $\mathrm{Br}$ Med $\mathrm{f}$ $1971 ;$ iii:747-51.

7 Albritton WL, Wiggins GL, Feeley JC. Neonatal listeriosis: distribution of serotypes in relation to age at onset of disease. $\mathcal{J}$ Pediatr 1976;88:481-3.

8 Jacobs MR, Stein H, Buqwane A, et al. Epidemic listeriosis; report of 14 cases detected in 9 months. SAfr Med f 1978;54:389-92.

9 Lennon D, Lewis B, Mantell C, et al. Epidemic perinatal listeriosis. Pediatr Infect Dis 1984;3: 30-4.

10 Evans JR, Allen AC, Stinson DA, Bortolussi R, Peddle LJ. Perinatal listeriosis: report of an outbreak. Pediatr Infect Dis 1985;4:237-41.

11 Rappaport F, Rabinovitz M, Toaff R, Krochik N. Genital listeriosis as a cause of repeated abortion. Lancet 1960;i:1273-5.

12 Macnaughton MC. Listeria monocytogenes in abortion. Lancet 1962;ii:484.

13 Ansbacher R, Borchardt KA, Hannegan MW, Boyson WA. Clinical investigation of Listeria monocytogenes as a possible cause of human fetal wastage. Am $\mathcal{F}$ Obstet Gynecol 1966;94:386-90. 4 Hood M. Listeriosis as an infection of pregnancy manifested in the newborn. Pediatrics 1961;72: 390-6.

15 Khong TY, Frappell JM, Steel HM, Stewart CM, Burke M. Perinatal listeriosis. A report of six cases. Br f Obstet Gynaecol 1986;93:1083-7.

16 Driscoll SG, Gorbach A, Feldman D. Congenital listeriosis: diagnosis from placental studies. Obstet Gynecol 1962;20:216-20.

17 Yamazaki K, Price JT, Altshuler G. A placental view of the diagnosis and pathogenesis of congenital listeriosis. Am $\mathcal{f}$ Obstet Gynecol 1977;129:703-5.

18 Larsson S, Linell F. Correlations between clinical and postmorten findings in listeriosis. Scand $\mathcal{F}$ Infect Dis 1979;11:55-8.

19 Halliday HL, Hirata T. Perinatal listeriosis-a review of twelve patients. Am $\mathcal{f}$ Obstet Gynecol 1979;133:405-10.

20 Gordon RC, Barrett FF, Clark DJ. Influence of several antibiotics, singly and in combination, on the growth of Listeria monocytogenes. $\mathcal{F}$ Pediatr 1972;80:667-70.

21 Hume OS. Maternal Listeria monocytogenes septicemia with sparing of the fetus. Obstet Gynecol 1976;48(suppl):33-4.

\section{Make way for the new genetics}

Although recombinant DNA technology may not be easy to understand, the new genetics is important for clinical practice. ${ }^{1}$ Much better information can be given to potential parents worried about genetic disease, while genetic diseases are increasingly preventable and may eventually be treatable.

The potential is vast and there are so many diseases that are mainly genetic in origin that one in 50 children suffers death or chronic disability from these. Premature coronary artery disease, cancer, and other common diseases also have an important genetic component and are candidates for renewed genetic exploration. For example, recent DNA studies with rare familial Alzheimer's presenile dementia ${ }^{2}$ and manic depressive psychosis ${ }^{3}$ have introduced a new genetic and biochemical approach to common psychiatric problems. At the present rate all genetic disorders will probably be mapped to their chromosomal location by the year $2000,{ }^{4}$ and most important genes will eventually be sequenced and their products identified. 